\title{
Necrotizing fasciitis of head - neck
}

\author{
Sudhangshu Shekhar Biswas ${ }^{1}$, Zaheer Al-Amin²
}

\begin{abstract}
:
Necrotizing Fasciitis of head -neck is not so uncommon in diabetic patients which is a progressive, destructive and potentially life threatening soft tissue infection primarily affecting superficial fascial planes. It is caused by group A streptococci or by a synergistic combination of aerobe and anaerobe micro organisms. This is a retrospective study which makes an attempt to analyze various parameters such as demography, aetiology, complications, and management methods determining the overall prognosis.

Odontogenic infection was the primary source of infection. Diabetes, anaemia, chronic renal failure and electrolyte imbalance were the most commonly associated illness. Surgical debridement with combined antibiotic therapy was used in the management of necrotizing fasciitis along with good control of diabetes and correction of anaemia and electrolyte imbalances. Overall mortality was low. The late referral and associated complications had increased the hospital stay. With proper control of infection by early diagnosis, surgical debridement and combined antibiotic therapy, along with timely control of complications and associated illness - better results can be possible.
\end{abstract}

Key words: necrotizing fasciitis, antibiotics, debridement

\section{Introduction:}

Necrotizing fasciitis was first described during the American civil war ${ }^{1}$. It is a rapidly spreading superficial infection involving the superficial fascia and subcutaneous tissue. The muscle and skin involvement, however, is unusual or minimal. Initially called 'hospital gangrene' by Joseph Jones in $1871^{2}$, the condition is frequently associated with post operative wounds of the perineum, abdomen and extremities. Meleney in 1924 considered subcutaneous necrosis as pathognomic features of necrotizing fascitis ${ }^{3}$. He noticed that Haemolytic Streptococci were frequent aetiological agents. Wilson was the first to use the term necrotizing fasciitis ${ }^{4}$.

Necrotizing fasciitis frequently involves the regions of the body include the extremitis ${ }^{5}$, genitalia and trunk and rarely involves the head and neck. Necrotizing fasciitis in head-neck commonly occurs secondary to dental infection but may follow foreign body impaction, trauma, peritonsillar abscess or insect bites. Diabetes, anaemia, malnourished and other immuno-compromised patients are at a risk for this

1. Registrar, ENT-Head \& Neck Surgery Deptt. BIRDEM, Dhaka, Bangladesh.

2. Professor and Head, ENT-Head \& Neck Surgery Deptt. BIRDEM, Dhaka, Bangladesh.

Correspondence to: Dr. Sudhangshu Shekhar Biswas, Registrar, ENT-Head \& Neck Surgery Deptt. BIRDEM, Dhaka, Bangladesh. condition $^{6}$. The principles of successful management include early diagnosis, broad spectrum antibiotics, radical surgical debridement and nutritional support with management of complications. If left untreated necrotizing fasciitis is associated with a high mortality rate.

We report 11 cases of necrotizing fasciitis of headneck regions taking into consideration the various clinical presentations, sources of infection, bacteriology, associated risk factors and ultimate outcome along with possible complications. An attempt was made to determine the factors responsible for a favourable outcome.

\section{Materials and methods:}

A retrospective review of the medical records of patient's with necrotizing fasciitis admitted to the Department of Otolaryngology, BIRDEM, Dhaka, from 1st January 2005 to 31st December, 2007 was done. The diagnosis of necrotizing fasciitis was based on either clinical and or surgical finding of extensive necrosis of the fascia and subcutaneous tissues or histological findings. A standardized instrumentation was done to abstract information from the medical records of each patient. Information was obtained under several broad categories- demographics, associated conditions, duration of symptoms prior to admission, microbiological data, antibiotic treatment, clinical features, surgical intervention and outcome. Information was tabulated and analyzed. 
Result:

Demographics: Eleven cases were found to fulfill the criteria of necrotizing fasciitis. The average age was 55.73 years (range $35-75$ years). The male to female ratio was 1.75: 1 (7 males and 4 females). Eight patients were 50 or over 50 years of age.

Table-I

Age, sex and Period elapsed between onset \& treatment

\begin{tabular}{lccc}
\hline SL No. & Age (yrs) & Sex & $\begin{array}{c}\text { Prior to treatment } \\
\text { (days) }\end{array}$ \\
\hline 1 & 60 & M & 13 \\
2 & 52 & F & 6 \\
3 & 35 & M & 4 \\
4 & 48 & M & 11 \\
5 & 40 & F & 14 \\
6 & 58 & M & 7 \\
7 & 56 & M & 3 \\
8 & 50 & F & 4 \\
9 & 67 & M & 14 \\
10 & 72 & F & 7 \\
11 & 75 & M & 9 \\
\hline
\end{tabular}

Source of infection: Primary odontogenic infection was the single most common source of infection: 7 out of 11 (66.63) cases. One developed necrotizing fasciitis following foreign body impaction in throat, one following peritonsillar abscess and one following an insect bite. One had no obvious source of infection (table-II).

Bacteriology: Number of microbial species isolated in each patient ranges in 0-4. Microbiological examination of infected tissue showed Staphylococcal Aureus in four cases, mixed aerobic gram positive and gram negative cocci in three cases, Klebsiella and â Haemolytic Streptococcus were found in one case each. MRSA was found in one case and one case showed no organism (table-II).
Table-II

Source of infection

\begin{tabular}{lll}
\hline SL No. & Source of infection & Bacteriology \\
\hline 1 & Dental & Mixed \\
2 & Dental & Klebsiella \\
3 & Dental & Gm. - ve \\
4 & F.B. throat & â Haemolytic Strepto. \\
5 & Dental & Mixed \\
6 & Dental & Staph Aureus \\
7 & Dental & Nil \\
8 & Dental & MRSA \\
9 & Peritonsillar abscess & Staph Aureus \\
10 & Idiopathic & Staph Aureus \\
11 & Insect bite & Staph Aureus \\
\hline
\end{tabular}

Site of infection \& extent of disease: Most of the cases had involvement of the neck with the submandibular triangle followed by the carotid triangle being the commonest sites. Spread to posterior triangle, anterior and posterior chest walls were noted in five cases each. The face, masseteric space, parotid region were involved in 3 cases. The least involved sites included the pre tracheal, parapharyngeal and retro pharyngeal spaces (table-III).

Table -III

Involved spaces

\begin{tabular}{lcc}
\hline Site Involved & $\begin{array}{c}\text { No. of } \\
\text { cases }\end{array}$ & $\begin{array}{c}\text { Percentage } \\
(\%)\end{array}$ \\
\hline Submandibular region & 9 & $81.81 \%$ \\
Carotid triangle & 8 & $72.72 \%$ \\
Submental region & 7 & $63.63 \%$ \\
Posterior triangle & 5 & $45.45 \%$ \\
Chest wall & 5 & $45.45 \%$ \\
Parotid space & 3 & $27.27 \%$ \\
Masseteric space & 3 & $27.27 \%$ \\
Face & 3 & $27.27 \%$ \\
Upper mediastinum & 2 & $18.18 \%$ \\
Parapharyngeal space & 2 & $18.18 \%$ \\
Pre-tracheal space & 2 & $18.18 \%$ \\
Retropharyngeal space & 2 & $18.18 \%$ \\
\hline
\end{tabular}


Associated disease: All our cases were Diabetic (100\%). So Diabetes Mellitus was the most common coexisting condition \& two cases presented with Diabetic Keto Acidosis. Anaemia was the most dominant finding with 9 out of 11 presenting é $\mathrm{Hb} \%$ less than $10 \mathrm{gm}$ percent. Four cases (36.36\%) associated é malnutrition. One each (9.09\%) coexisted with chronic renal failure, positive HBsAg serology \& pulmonary diseases (table-IV).

Table IV

Associate disease

\begin{tabular}{lcc}
\hline Condition associated & $\begin{array}{c}\text { Pt. affected } \\
\text { (case No.) }\end{array}$ & $\begin{array}{c}\text { No. of } \\
\text { cases }\end{array}$ \\
\hline Diabetes Mellitus & All & $11(100 \%)$ \\
Anaemia & Cases 1,2,3,5, & $9(81.81 \%)$ \\
Malnutrition & $6,7,8,9,11$ & \\
CRF & Cases1,2,3,5 & $4(36.36 \%)$ \\
HBsAg +ve & Case 5 & $1(9.09 \%)$ \\
Hypertention & Case 4 & $1(9.09 \%)$ \\
Ch. Bronchitis & Case 2 & $1(9.09 \%)$ \\
Bronchial asthma & Case 3 & $1(9.09 \%)$ \\
\hline
\end{tabular}

Management \& outcomes: A multimodality treatment approach was adopted to deal with this acute life threatening condition at our institution (table-V).

Antibiotic therapy: The most commonly used antibiotic regimen was Benzyl Penicillin (20 Lac I.V. 6 hourly) along with a third generation Cephalosporin (1 gm I.V. twice daily) \& Metronidazol (500mgl.V. thrice daily). Three cases were given Gentamycin (80mg I.V. thrice daily). Then the antibiotics were changed according to the culture \& sensitivity reports.

Table- V

Treatment approach

\begin{tabular}{ll}
\hline $\begin{array}{l}\text { General assessment } \\
\text { Correction \& }\end{array}$ & $\begin{array}{l}\text { Intravenous antibiotics } \\
\text { Triple antibiotic therapy like } \\
\text { control of: }\end{array}$ \\
$\begin{array}{l}\text { Inj. Benzyl Penicillinn } \\
\text { Inj. 3rd generation cephalosporinn }\end{array}$ \\
$\begin{array}{l}\text { Diabetes } \\
\text { Hypertensionn }\end{array}$ & -gram netronidazol for- gram positive \\
Fluid \& & aerobes \\
electrolyte & For-pulmonary complication \\
imbalance & Inj. Gentamycin was given \\
Radiology: & \\
CXR & \\
CT Scan & \\
\hline
\end{tabular}

Surgical treatment: The most of our cases (8 out of 11) underwent radical surgical debridement that included resection of all devitalized tissues like skin, fascia, muscles, glands. all our cases underwent multiple minor surgical debridements. One case required tracheostomy to maintain the airway. Skin grafting was done to cover the wound gaps in four cases. Majority of the wounds were closed by secondary suturing (table $\mathrm{VI}$ ).

\section{Table VI}

Surgery (wide and extensive debridement)

Major: (performed under $\mathrm{G} / \mathrm{A}$ ) radical in type Including resection of necrosed fascia, skin, glands, muscles and subcutaneous tissues

Minor: (performed under L/A)Irrigation with 1\% $\mathrm{H}_{2} \mathrm{O}_{2}$, Resction of necrosed tissueThorough irrigation é antibiotic solution \& isotonic saline initially 2-3 times/ day for 5 daysLater on once daily

Others: Tracheostomy: Emergency Dental extraction (gross carries teeth)

Outcomes: Only one patient died out of 11 cases that underwent treatment for necrotizing fascitis. The patient had septicaemia with multi organ failure. Uncontrolled diabetes mellitus with ketoacidosis was also noted in this case (table-VII).

Complications \& total hospital stay: After initial surgical debridement four cases developed submandibular gland necrosis and one case of the parotid gland necrosis. Four cases showed myonecrosis. One case developed a left sided lateral pharyngeal wall fistula following debridement. Skin necrosis occurred in all cases. Septicaemia was diagnosed in 3 out of 11 cases of necrotizing fasciitis. Acute renal failure was recorded in two cases. One patient had myocardial infarction é left ventricular failure.

Total hospital stay ranged from 14-62 days with an average of 27.09 days. Those having one or other complications had a long stay compared to other without (table-VII). 
Table-VII

Management \& outcome:

\begin{tabular}{|c|c|c|c|c|c|c|}
\hline $\begin{array}{l}\text { SI } \\
\text { No }\end{array}$ & major & minor & $\begin{array}{l}\text { Total } \\
\text { hosp. } \\
\text { days }\end{array}$ & Complication & $\begin{array}{c}\text { Out } \\
\text { come }\end{array}$ & $\begin{array}{l}\text { Recon- } \\
\text { struction }\end{array}$ \\
\hline 1 & 1 & 7 & 35 & $\begin{array}{l}\text { S.M.* gland necrosis, } \\
\text { uncontrolled D.M.** }\end{array}$ & Alive & Split thickness skin graft \\
\hline 2 & Nil & 2 & 33 & $\begin{array}{l}\text { Masseteric muscle necrosis, parotid } \\
\text { Gland necrosis }\end{array}$ & Alive & Nil \\
\hline 3 & 1 & 5 & 37 & $\begin{array}{l}\text { Sepsis, hge†, strap \& S.M. } \\
\text { muscle Ncr††. }\end{array}$ & Alive & Rhomboid rotation flap \\
\hline 4 & 1 & 8 & 62 & $\begin{array}{l}\text { ARF }^{\star \star *} \text {, Superior Mediastinitis, } \\
\text { Sepsis, MODS }{ }^{\star \star \star \star}, D K A^{\star \star \star \star \star \star}\end{array}$ & Died & Nil \\
\hline 5 & Nil & 4 & 14 & Nil & Alive & Nil \\
\hline 6 & 1 & 3 & 22 & $\begin{array}{l}\text { LVF, Necrosis of strap muscles } \\
\text { S.M. gland, }\end{array}$ & Alive & Nil \\
\hline 7 & 1 & 6 & 15 & Masseteric M. necrosis, ARF & Alive & Nil \\
\hline 8 & 1 & 7 & 21 & Lateral pharyngeal wall fistula. & Alive & Split thickness skin graft \\
\hline 9 & 1 & 3 & 25 & Necrosis of S.M. gland & Alive & Nil \\
\hline 10 & Nil & 5 & 15 & Nil & Alive & Nil \\
\hline 11 & 1 & 7 & 19 & Nil & Alive & Nil \\
\hline
\end{tabular}

*SM- Sub Mandibular

** DM- Diabetes Mellitus

${ }^{* * * A R F-~ A c u t e ~ R e n a l ~ F a i l u r e ~}$

**** MODS- Multi Organ Dysfunction Syndrome

*****DKA- Diabetic Keto Acidosis

hge $^{\star *}$-Haemorrhage

Ncr**- Necrosis

\section{Discussion:}

Necrotizing fasciitis is a rapidly spreading and potentially fatal infection initially involving the superficial musculoaponeurotic system and superficial fascial planes, eventually resulting in septicaemia, multiorgan failure and ultimately death if inadequately treated. In head-neck region the involvement is fortunately rare. Rarity of the condition can be reflected by the fact that only 67 cases were reported between 1945-19903.

After 1990, due to increasing awareness of the condition, rate of involvement of necrotizing fasciitis became gradually declining. Stone and Martin in $1972^{7}$ reviewed 63 cases of necrotizing soft tissue infection and found only two involving the neck.
Lin et al. identified 47 cases involving the head\& neck region during their 12 years analysis ${ }^{8}$. In this study we analyze 11 cases primarily involving the face and cervical region during the period of 3 years (2005-2007).

The average mean age in this study was 55.73 years which was nearer to the mean age of Necrotizing fasciitis involving other areas of the body ${ }^{10}$. Primary dental infection remains a major cause of the condition affecting $63.63 \%$ of cases (7 out of 11 cases). This is agreed with other study ${ }^{10}$. Less common causes such as insect bites ${ }^{11}$, trauma and peritonsillar abscess ${ }^{12}$ have been described occasionally as a source of the severe soft tissue infection.

It is originally believed that Necrotizing fasciitis occurs secondary to group A Sreptococcal \& Staphylococcal infections. The concept of a combination of aerobic 
and anaerobic is considered more appropriate ${ }^{13}$. In our study only four out of eleven cultures showed Staphylococcal infections and three out of eleven showed mixed (more than two) organisms and only one of the cultures grew group A Sreptococcus.

Lin et $\mathrm{al}^{9}$ observed diabetes mellitus as the most commonly associated disease affecting $72.3 \%$ of the cases almost agreed with our study where all the cases of Necrotizing fasciitis were associated with diabetes mellitus. Hypertension, alcoholism and obesity were the other common systemic disorders considered to compromise the body's immunity ${ }^{14}$. Out of the eleven patients we studied a significant number of cases (9 out of 11) had aneamia at the time of presentation. Its importance is reflected by the fact that anaemia results in poor wound healing and decreased body resistance to the disease thus increasing the total duration of hospital stay.

Benzyl Penicillin is still the first line of defense along with third generation Cephalosporin and Metronidazol. This is in agreement with several reports of the success of penicillin in the treatment of the condition ${ }^{15}$. Amynoglycosides, for better gram negative coverage. Triple antibiotic therapy along é excision and extensive surgical debridement of fascia, skin, subcutaneous tissue along with involved glands and muscles remain an important step in the management. Stock et $\mathrm{al}^{16}$, Bahu et $\mathrm{al}^{17}$ and other ${ }^{18}$ advocated multiple debridements for a better outcome.

Nohekwe et al ${ }^{19}$ in their series considered multiple factors such as pre existing systemic illness, late surgical intervention, septicaemia with in 24 hours, mediastinal and thoracic extension of the infection as responsible for an increase in overall mortality. Wenig et $\mathrm{al}^{12}$ speculated that diabetes mellitus impaired urine continence were important factors in decreasing the survival rate. In our study only one out of 11 cases studied, died of the disease placing the overall mortality at $9.09 \%$.

Uncontrolled diabetes with ketoacidosis in one out of 11. This might have aggravated the primary disease by causing supression of the immune system thus leading to septicaemia and multi organ failure, strengthening the speculations of Wenig et al ${ }^{12}$. Complications range from simple skin and muscle necrosis to septicaemia and multi organ failure.

Vascular complications such as facial artery necrosis and jugular vein thrombosis were rarely reported in this literature. Catastrophes related to the carotid artery such as aneurysm, rupture, thrombosis with hemiplagia ${ }^{19}$ were not recorded in our series. The longer the period that elapsed between onset and surgical intervention, the higher the complication rate.

\section{Conclusion:}

The better result can be achieved in Necrotizing Fasciitis by using aggressive medical and surgical management. Diabetes mellitus, anaemia, old age, co-existing pulmonary diseases, delayed referral and late surgical intervention are some factors, which determine the eventual prognosis. Early diagnosis of disease recognition of possible complication and prompt surgical intervention help to decrease mortality and morbidity thereby providing a good outcome.

\section{References:}

1. Jones J. Investigations upon the nature, causes and treatment of hospital gangrene as it prevailed in the confiderate armies. In: surgical memories of the war of rebellion. New York: united states sanitary commission , 1871.

2. Jones J. Investigations upon the nature, causes and treatment of hospital gangrene as it prevailed in the confiderate armies 1861-1865. In: Hamilton $\mathrm{FH}$, ed. Surgical Memories of the War of Rebellion. Riverside, N. Y.: Hurd and Houghton, 1870-1871; 146-70

3. Meleney FL. Haemolytic streptococcal gangrene. Arch Surg, 1924; 9: 317

4. Banerjee AR, Murty GE, Moir AA. Cervical necrotizing fascitis: A distinct clinicopathological entity? J Larynol Otol, 1996; 110: 81

5. Casali RE, Tucker WE, Petrino RA, et al. postoperative necrotizing fascitis of the abdominal wall. Am J Surg, 1980; 140: 787-790.

6. Bilton BD, Zibari GB, Mc.Millan RW, Aultman DF, Dunn G, Mcdonald JC. Aggressive surgical management of necrotizing fascitis serves to decrease mortality: A retrospective study. Am Surg, 1998; 64: 397-401.

7. Stone $\mathrm{HH}$, Martin JD. Synergistic necrotizing cellulites. Ann Surg, 1972; 175: 702-10

8. Lin C, Yeh FL, Lin JT, Ma h, Hwang Ch, Shen $\mathrm{BH}$, et al. Necrotizing Fascitis of the head and neck: An analysis of 47 cases. Plast Reconstructr Surg, 2001; 107: 1684-93 
9. Francis KR, Lamuate HR, Davis JM, Pizzi Wf. Implications of risk factors in necrotizing fascitis. Am J Surg, 1993;9:304-8.

10. Skorina J, Kaufman D. Necrotizing fasciitis originating from pinna perichondritis. Otolaryngol Head Neck Surg, 1995;113:445-9.

11. Balina M, Canalis RF. Necrotizing fasciitis (streptococcal gangrene) of the face. Arch otolaryngol, 1980;106:648.

12. Wenig BL, ShikowitzMJ, Abramson AL. Necrotizing fasciitis as a lethal complication of peritonsillar abscess. Laryngoscope, 1984; 94 : 1576-9.

13. Moss RM, Kunpittaya S, Sorasuchand A. Cervical Necrotizing fasciitis : an uncommon sequela to dental infection. Ann otol Rhinol Laryngol, 1990; 99: 643a-6.

14. Krespi YP, Lawson W, Blaugrund SM, Biller HF. Massive necrotizing infection of the neck. Head Neck Surg, 1981; 3: 475.
15. Javenicus RV, Hann SE, Batt MD, Necrotizing fasciitis. Surg gynecol obstet, 1982; 154: 97.

16. Stock CR, Winstead W, Marinez SA. Odontogenic necrotizing fasciitis in lle-Ife, Nigeria. $\mathrm{Br} J$ oral maxillofac Surg 2002; 40: 64-7.

17. Bahu SJ, Shibuya TY, Meleca RJ, Mathog RH, Yoo GH, Stachler RJ, et al. craniocervical necrotizing fasciitis : An 11 year experience. Otolaryngol Head Neck Surg, 2001; 125: 245-52.

18. Majeski JA, Alexander JW. Early diagnosis, nutritional support and immediate extensive debridement improve survival in necrotizing fasciitis . Am J Surg, 1983;145:784-7.

19. Ndukwe KC, Fatusi OA, Ugboko VI. craniocervical necrotizing fasciitis in Ile-Ife, Nigeria. Br J oral maxillofac Surg, 2002; 40: 64-7. 